\title{
PRELIMINARY OUTCOME COMPARISON OF FLEXIBLE URETERO-RENOSCOPIC LASERTRIPSY VERSUS PCNL IN THE TREATMENT OF STAGHORN CALCULI
}

Vincent Koo, Mussammet Ahmed, Aniket Deshpande, and Ahmed Kodera

Department of Urology, Alexandra Hospital, Worcestershire Acute Hospitals NHS Trust, United Kingdom

Correspondence: Vincent Koo: v.koo@nhs.net

Submitted: June 8, 2020. Accepted: June 23, 2020. Published: July 23, 2020.

\begin{abstract}
Percutaneous nephrolithotomy (PCNL) is a well-established treatment for staghorn stones. Given the improvement in technology and techniques of flexible ureterorenoscopic lasertripsy (FURS), we retrospectively compared its treatment outcome against PCNL for staghorn stones at our institution.
\end{abstract}

\section{Materials and Methods}

All patients with partial and complete staghorn stones treated by FURS or PCNL between December 2014 and December 2017 were included. Outcome measures included the duration of the procedure, length of stay, retreatment rate, auxiliary rate, complications, and clinical success rates (stone or dust-free status).

\section{Results}

Out of 22 staghorns, 10 (1 complete, 9 partial) had FURS and 12 (2 complete and 10 partial) had PCNL. Comparatively, the FURS group were older (mean 70.1 vs. 57.1 years, U-test $\mathrm{p}<0.001$ ) with higher mean ASA scores (mean 2.3 vs. 1.5, U-test, $\mathrm{p}=0.04$ ), with a similar body-mass index (mean 29.1 vs. 27.3), maximum stone size (29.7 vs. $34.6 \mathrm{~mm}$ ) and Hounsfield unit ( 836 vs. $891 \mathrm{HU}$ ).

FURS was quicker to clinical success $(102.4 \mathrm{~min}$ vs. $159.5 \mathrm{~min}$, U-test $\mathrm{p}<0.001)$ and had shorter hospital stay $(1.1 \mathrm{~d}$ vs. $3.5 \mathrm{~d}$, U-test $\mathrm{p}<0.001)$. Higher primary procedure success $[80 \% \mathrm{vs} .36 \%, 95 \% \mathrm{CI}=(-3.0 \%$, $74.5 \%)]$, higher overall success $[90 \%$ vs. $73 \%, 95 \% \mathrm{CI}=(-22 \%, 51 \%)]$, similar retreatment rate $(10 \%)$, and higher auxiliary treatment rate (100\% vs. $18 \%)$ were observed. 1 patient from FURS had a small intraparenchymal aspect of staghorn inaccessible to a laser. There were no complications in the FURS group. In the PCNL group, one developed a pseudoaneurysm requiring embolization, and 1 had failed PCNL access (excluded from the statistical calculation).

\section{Conclusion}

Our preliminary data suggest that FURS is efficacious and safe for staghorn stones treatment, and comparable to PCNL. In this context, we highlight FURS potential role as first-line management of staghorn stones.

Keywords: Staghorn stone, partial staghorn stone, flexible ureteroscopy, PCNL, lasertripsy

Staghorn stones are complex by its advanced stone formation nature and its large stone burden with branching distribution in the collective system of the kidney. In our unit, it makes up less than 5\% of our urinary stone-related work. Traditionally, flexible ureterorenoscopic (FURS) lasertripsy is not the recommended first-line treatment for staghorn stones because of the inability to clear the stone burden at first treatment and the risk of sepsis. With the improvement in scope technology and techniques

J Endolum Endourol Vol 3(2):e31-e36; July 23, 2020.

This article is distributed under the terms of the Creative Commons Attribution-Non

Commercial 4.0 International License. CKoo, et al. 
first described previously, ${ }^{1}$, and also patient choice, we have had success at primary clearance of staghorn stones with FURS. We present our preliminary FURS versus PCNL outcomes in the treatment of staghorn stones and review the current literature.

\section{METHODS}

All patients with partial and complete staghorn stones treated by FURS or PCNL between December 2014 and December 2017 were included. The definition of staghorn stones was adopted from previous literature, ${ }^{2}$ whereby a complete staghorn was defined as one that filled all calyces and renal pelvis, or filled $\geq 80 \%$ of the collecting system. A partial staghorn was defined as one that filled the renal pelvis and at least 2 or more calyces. Outcome measures included duration of procedure, length of stay, retreatment rate, auxiliary rate, complications, and (primary and overall) clinical success rates (defined as stone or dust-free status). We used FACIT-TS questionnaire to determine treatment satisfaction for FURS group. SPSS, version 17.0 (SPSS, Inc., Chicago, IL, USA) and $\mathrm{R}$ version 3.6.0 were used for statistical analysis. The Mann-Whitney U-test was used to compare continuous data between two independent groups. $P<0.05$ was considered statistically significant. Exact two-sided confidence intervals for the difference between two independent proportions (for primary clearance and overall clearance rate) were obtained using package ExactCIdiff from R. ${ }^{3}$

\section{FURS}

The flexible ureterorenoscopic lasertripsy (FURS) procedure was done in lithotomy position with Bair Hugger ${ }^{\mathrm{TM}}$ (3M, USA) normothermia system and Flowtrons ${ }^{\circledR}$ (Arjo Hunleight, Sweden) intermittent pneumatic compression device. 7F Karl-Storz ${ }^{\circledR}$ Semirigid Ureteroscopy was routinely done to survey the ureter and to dilate the ureteric orifice under direct vision. Boston Scientific Navigator ${ }^{\mathrm{TM}} 36 \mathrm{~cm}$ or $46 \mathrm{~cm}$
11/13F ureteric access sheath was used. Either KarlStorz ${ }^{\circledR}$ FlexXCS ${ }^{\mathrm{TM}}$ or Boston Scientific Lithovue flexible ureterorenoscopy was performed. Lasertripsy was done using 200um Boston Scientific Flexiva ${ }^{\mathrm{TM}}$ Tractip laser fibre, with short and long pulse at 1.2J$1.5 \mathrm{~J} \times 10 \mathrm{~Hz}-15 \mathrm{~Hz}$ from EMS Swiss LaserClast ${ }^{\circledR}$ (Nyon, Switzerland). All patients were stented and catheterized postoperatively. Catheter was removed in the morning the following day. A postop KUB $\mathrm{x}$-ray was done the next day. The ureteric stent was removed about 4 weeks postop. Follow up CTKUB/ KUB x-ray was done at 4-6 months.

\section{PCNL}

The percutaneous nephrolithotomy (PCNL) procedure was performed initially in lithotomy for placement of the ureteric catheter, then repositioned to semi-prone for fluoroscopic-guided single percutaneous access usually in the lower pole kidney, performed by a radiologist, using Boston Scientific NephroMaxTM 30F balloon dilator system. Nephroscope was used with EMS Swiss LithoClast ${ }^{\circledR}$ (Nyon, Switzerland), combined with flexible nephroscopy (Olympus CYFV Flexible cystoscope) with lasertripsy as required. Upon conclusion, a large-bore 20-26F nephostomy tube was placed. A nephrostogram was done before the removal of nephrostomy tube. Follow up CTKUB/ KUB x-ray was done at 4-6 months.

\section{RESULTS}

Out of 22 staghorns, 10 (1 complete, 9 partial) had FURS and 12 (2 complete and 10 partial) had PCNL. One patient from the PCNL group was excluded due to failed PCNL access. Comparatively, the FURS group were older (mean 70.1 vs. 57.1 years, U-test $p<0.001$ ) with higher mean ASA scores (mean 2.3 vs. 1.5 , U-test, $\mathrm{p}=0.04$ ), with similar BMI (mean 29.1 vs. 27.3), maximum stone size (29.7 vs. $34.6 \mathrm{~mm})$ and Hounsfield unit (836 vs. $891 \mathrm{HU})$ as shown in Table 1. 
TABLE 1 Comparative Stone Patient Characteristic

\begin{tabular}{|c|c|c|}
\hline Comparative data & FURS $(n=10)$ & $\operatorname{PCNL}(n=11)$ \\
\hline $\begin{array}{l}\text { Mean age (range) } \\
\text { Sex (Male: Female) } \\
\text { Mean BMI }\end{array}$ & $\begin{array}{c}70.1(53-83) \\
5: 5 \\
29.1\end{array}$ & $\begin{array}{c}57.1(31-83) \\
7: 4 \\
27.3\end{array}$ \\
\hline $\begin{array}{l}\text { Mean ASA grade: } \\
\text { ASA1 } \\
\text { ASA2 } \\
\text { ASA3 } \\
\text { ASA4 }\end{array}$ & $\begin{array}{c}2.3 \\
2 \\
4 \\
3 \\
1\end{array}$ & $\begin{array}{c}1.5 \\
6 \\
5 \\
0 \\
0\end{array}$ \\
\hline $\begin{array}{l}\text { Stone data: } \\
\text { Complete staghorn } \\
\text { Partial Staghorn } \\
\text { Mean max stone size }(\mathrm{mm}) \\
\text { Mean Hounsfield unit }\end{array}$ & $\begin{array}{c}1 \\
9 \\
29.7 \\
863\end{array}$ & $\begin{array}{c}2 \\
9 \\
34.6 \\
891\end{array}$ \\
\hline $\begin{array}{l}\text { Preop drainage: } \\
\text { Nil } \\
\text { Nephrostomy } \\
\text { Stent }\end{array}$ & $\begin{array}{l}9 \\
0 \\
1\end{array}$ & $\begin{array}{l}9 \\
0 \\
2\end{array}$ \\
\hline Mean duration of surgery(mins) & 102.4 & 159.5 \\
\hline Mean length of hospital stay (range) & 1.1 (1-2days) & 3.5 (2-5days) \\
\hline $\begin{array}{l}\text { Monotherapy complete clearance } \\
\text { Repeat treatment } \\
\text { Auxillary treatment } \\
\text { Overall clearance }\end{array}$ & $\begin{array}{c}8(80 \%) \\
1(10 \%) \\
10(100 \%) \\
9(90 \%)\end{array}$ & $\begin{array}{l}3(36 \%) \\
1(10 \%) \\
2(18 \%) \\
7(73 \%)\end{array}$ \\
\hline $\begin{array}{l}\text { Complications: } \\
\text { Sepsis } \\
\text { Pseudoaneursym requiring } \\
\text { embolization } \\
\text { None }\end{array}$ & $\begin{array}{l}0 \\
0\end{array}$ & $\begin{array}{l}0 \\
1\end{array}$ \\
\hline $\begin{array}{l}\text { Stone analysis: } \\
\text { Mixed calcium oxalate/phosphate } \\
\text { Calcium phosphate } \\
\text { Uric acid } \\
\text { Triple phosphate }\end{array}$ & $\begin{array}{l}4 \\
3 \\
2 \\
1\end{array}$ & $\begin{array}{l}6 \\
1 \\
4 \\
0\end{array}$ \\
\hline
\end{tabular}

ASA = American Society of Anesthesiologist physical status classification; BMI = body mass index 
All the FURS cases, barring one case, were not prestented. FURS was quicker to clinical success (102.4 min vs. $159.5 \mathrm{~min}, \mathrm{U}$-test $\mathrm{p}<0.001$ ), had shorter mean length of hospital stay ( $1.1 \mathrm{~d}$ vs. $3.5 \mathrm{~d}$, U-test $\mathrm{p}<0.001$ ), higher primary procedure clinical success $(80 \%$ vs. $36 \%, 95 \%$ $\mathrm{CI}=[-3.0 \%, 74.5 \%])$, higher overall success $(90 \% \mathrm{vs}$. $73 \%, 95 \% \mathrm{CI}=[-22 \%, 51 \%])$, and similar retreatment $(10 \%)$ and higher auxiliary treatment (100\% vs. $18 \%)$. The $100 \%$ auxiliary treatment for FURS group, were all stent removal procedures. Out of the stent removal in the FURS group, $4(40 \%)$ had a general-anesthetic procedure for stent removal and concurrent flexible ureteroreno-scopy with washout of any remaining dust.

No patients in either group required blood transfusion. There were no complications or readmissions in the FURS group. In the PCNL group, one developed a pseudoaneurysm requiring embolization, and 1 had failed PCNL access (excluded from the statistical calculation). The FACIT-TS showed an overall treatment satisfaction score of $94.8 \%$, a treatment recommendation score of $90 \%$, and $100 \%$ would have chosen the same FURS treatment again.

\section{DISCUSSION}

This is the first comparative case series of FURS vs PCNL in the treatment of staghorn stones, favouring FURS as an acceptable first-line treatment option in our hands. Our PCNL overall clinical success was comparable to national PCNL data of $47 \%$ for staghorn stones, ${ }^{2}$ but lower than international literature. This was likely due to the reliance of single puncture and also at least 4 patients (36\%) chose conservative management of their small residual stones.

When comparing with international PCNL results, our FURS monotherapy and overall clinical success rate were equivalent. Published case series showed PCNL monotherapy success for staghorn clearance varies at $49 \%,{ }^{5} 56.6 \%,{ }^{6} 78 \%,{ }^{7} 54 \%,{ }^{2}$ and $84 \% .8$ Subsequent overall clearance improved with further retreatment or/and auxiliary treatment, again reflected similar comparable result of our FURS at $90 \%$ vs. $74 \%,{ }^{5}, 72.5 \%,{ }^{6} 91 \%,{ }^{7} 94 \%,{ }^{8} 96.3 \%{ }^{2}$ In the 1 case of FURS, where stone-free was not achieved, it was never the intention to clear this lower pole intraparenchymal part of a calcified scar at the periphery of the kidney (to avoid potential fistula). Follow up of this case for a further 4 years did not show any staghorn recurrence or further extension of the calcified scar. It was notable that the patient's urinary tract infection and hematuria symptoms completely settled after FURS treatment. Hence from the patient's perspective, this case was deemed to be successful.

TABLE 2 FURS versus PCNL Comparative Performance Data

\begin{tabular}{|c|c|c|c|c|}
\hline Author / performance & $\begin{array}{l}\text { Mean operative } \\
\text { time (Mins) }\end{array}$ & Length of stay (days) & $\begin{array}{l}\text { Monotherapy } \\
\text { success }\end{array}$ & Overall success \\
\hline Koo et al, 2020 & $102.4(60-131)$ & $1.1(1-2)$ & $80 \%$ & $90 \%$ \\
\hline Zhao et al $2016^{* 10}$ & $129.6(76-153)$ & $\mathrm{n} / \mathrm{a}$ & $45.5 \%$ & $84.2 \%$ \\
\hline El-Nahas et al, $2012^{6}$ & $\mathrm{n} / \mathrm{a}$ & $5.2(2-21)$ & $56.6 \%$ & $72.5 \%$ \\
\hline Soucy et al, $2009^{7}$ & $104(35-241)$ & $\begin{array}{c}5 \text { (range } 1-23 \text { for partial, } \\
1-30 \text { for complete) }\end{array}$ & $78 \%$ & $91 \%$ \\
\hline Desai et al, $2009^{\star \star 2}$ & $112.5(55-310)$ & $7.1(4-28)$ & $54 \%$ & $96.3 \%$ \\
\hline Aron et al, $2005^{8}$ & $146(100-180)$ & 4 (range $2-16)$ & $84 \%$ & $94 \%$ \\
\hline
\end{tabular}

${ }^{\star}$ Single-stage multi-tract Mini-PCNL results.

** Results from group III result $(n=373)$ done between 2002 and 2008.

J Endolum Endourol Vol 3(2):e31-e36; July 23, 2020.

This article is distributed under the terms of the Creative Commons Attribution-Non

Commercial 4.0 International License. @Koo, et al. 
Newer developments in PCNL techniques and technology include smaller size instruments, smaller calibre PCNL tracts, and combined approaches, have not increased overall clearance success, but a trend of less complication and earlier hospital discharge has been noted. This only highlights the challenges and complexity of staghorn stone treatment. The combined approach of PCNL and FURSs in the same anesthetic sitting have yielded good overall staghorn clearance of 87.9\%.9 2-staged mini-PCNL for staghorn treatment yielded an overall clearance of $84.2 \% .^{10}$

Our initial FURS demonstrated a very good safety profile with no complication, even when performed in higher risk ASA 3/4 and older patients. The inherent safer nature of minimally endoscopic surgery and as such, complications are minimal compared to the PCNL literature (Table 3). All of the FURS cases required ureteric stent insertion due to the duration of surgery, the use of ureteric access sheath, and stone dust burden postoperatively. Arguably the postoperative stent symptoms, for an average stent dwelling time of 4 weeks, was a justifiable compromise for an earlier hospital discharge and undergoing an endoscopic procedure associated with fewer complications.

The main limitation of this study is the small number of non-randomized cases. This small number reflects the developmental stages of FURS technique for staghorn calculi. It does show some early promising results. Also, another limitation is that majority of the FURS cases were done on partial staghorn calculi. Whilst it was appropriate to compare with our local PCNL data, and the outcome results may have likely been more favourable when compared to international series on PCNL, done mainly on complete staghorn calculi. Nevertheless, it provides the proof of concept and the first documented comparable success of FURS to the accepted standard PCNL in the treatment of staghorn stones. Future work should focus on a larger number of cases of both partial and complete staghorn treated by FURS, to confirm the similar good and durable outcome.

TABLE 3 FURS versus PCNL Comparative Complication Data

\begin{tabular}{|c|c|c|c|c|c|c|}
\hline Complication/Authors & $\begin{array}{l}\text { Koo et al, } \\
2020\end{array}$ & $\begin{array}{l}\text { Desai et al, } \\
2009^{2}\end{array}$ & $\begin{array}{l}\text { Aron et } \\
\text { al, } 2005^{8}\end{array}$ & $\begin{array}{c}\text { Soucy et al, } \\
2009^{7}\end{array}$ & $\begin{array}{l}\text { El-Nahas } \\
\text { et al, 2012 }\end{array}$ & $\begin{array}{c}\text { Zhao et al, } \\
2016^{10}\end{array}$ \\
\hline Fever & 0 & $24.9 \%$ & $21 \%$ & - & $2.5 \%$ & $17.9 \%$ \\
\hline Perinephric collection & 0 & $3.2 \%$ & - & - & $0.8 \%$ & - \\
\hline UTI & 0 & $6.2 \%$ & - & - & - & - \\
\hline Septic shock & 0 & - & $0.8 \%$ & - & - & $15.2 \%$ \\
\hline Blood transfusion & 0 & $14.5 \%$ & $14.9 \%$ & $0.8 \%$ & $14 \%$ & $9.7 \%$ \\
\hline $\begin{array}{l}\text { Perforation pelvicalyceal } \\
\text { system / extravasation }\end{array}$ & 0 & $4.5 \%$ & $4.1 \%$ & - & $2.5 \%$ & - \\
\hline Urinary leakage & 0 & - & $4 \%$ & - & $4.5 \%$ & - \\
\hline Angioembolisation & 0 & - & $1.6 \%$ & $0.2 \%$ & $3.4 \%$ & $4.1 \%$ \\
\hline Colonic injury & 0 & $0.25 \%$ & - & - & - & - \\
\hline Pneumo/hydrothorax & 0 & $0.25 \%$ & $7.1 \%$ & $1.4 \%$ & $1.7 \%$ & - \\
\hline Death & 0 & 0 & 0 & $0.2 \%$ & $0.4 \%$ & 0 \\
\hline
\end{tabular}

${ }^{*}$ Single-stage first session Mini-PCNL results.

${ }^{* *}$ Results from group III result $(n=373)$ done between 2002-2008.

J Endolum Endourol Vol 3(2):e31-e36; July 23, 2020.

This article is distributed under the terms of the Creative Commons Attribution-Non

Commercial 4.0 International License. @Koo, et al. 


\section{CONCLUSION}

Our preliminary data suggest that FURS is efficacious and safe for staghorn stones treatment, and comparable to PCNL. In this context, we highlight FURS potential role as first-line management of staghorn stones.

\section{CONFLICT OF INTEREST}

None declared

\section{REFERENCES}

1. Koo V. Single-stage flexible uretero-renoscopic lasertripsy clearance of Staghorn Stone. ARC J Urol 2017;2(3):12-14 doi: dx.doi.org/ 10.20431/2456-060X.0203003.

2. Desai M, Jain P, Ganpule A, et al. Developments in technique and technology: the effect on the results of percutaneous nephrolithotomy for staghorn calculi. BJU Int 2009;104(4):542-8.

3. Shan $\mathrm{G}$ and Wang W. ExactCIdiff: Inductive Confidence Intervals for the difference between two proportions. R package version 1.3. 2013. Available at: https:// CRAN.R-project.org/package $=$ ExactCIdiff.

4. Armitage JN, Irving SO, Burgess NA; British Association of Urological Surgeons Section of Endourology. Percutaneous nephrolithotomy in the United
Kingdom: results of a prospective data registry. Eur Urol 2012;61(6):1188-93.

5. Al-Kohlany KM, Shokeir AA, Mosbah A, et al. Treatment of complete staghorn stones: a prospective randomizedcomparison of open surgery versus percutaneous nephrolithotomy. J Urol 2005;173(2):469-73.

6. El-Nahas AR, Eraky I, Shokeir AA, et al. Percutaneous nephrolithotomy for treating staghornstones: 10 years of experience of a tertiary-care centre. Arab J Urol 2012;10(3):324-9.

7. Soucy F, Ko R, Duvdevani M, et al. Percutaneousnephrolithotomy for staghorn calculi: a single center's experience over 15 years. J Endourol 2009;23(10):1669-73.

8. Aron M, Yadav R, Goel R, et al. Multi-tract percutaneous nephrolithotomy for large complete staghorn calculi. Urol Int 2005;75(4):327-32.

9. Wen J, Xu G, Du C, Wang B. Minimally invasive percutaneous nephrolithotomy versus endoscopic combined intrarenal surgery with flexible ureteroscope for partial staghorn calculi: A randomized controlled trial. Int J Surg 2016;28:22-7.

10. Zhao Z, Cui Z, Zeng T, et al. Comparison of 1-stage with 2-stage multiple-tracts mini-percutaneous nephrolithotomy for the treatment of staghorn stones: a matched cohorts analysis. Urology 2016;87:46-51.

J Endolum Endourol Vol 3(2):e31-e36; July 23, 2020.

This article is distributed under the terms of the Creative Commons Attribution-Non

Commercial 4.0 International License. CKoo, et al. 